\title{
(6) \\ The challenge of crafting policy for do-it-yourself brain stimulation
} OPEN ACCESS

\author{
Nicholas S Fitz, Peter B Reiner
}

National Core for Neuroethics, University of British Columbia, Vancouver, British Columbia, Canada

\section{Correspondence to} Professor Peter B Reiner, National Core for Neuroethics, University of British Columbia, 2211 Wesbrook Mall, Vancouver, BC, Canada V6] 2B5; peter.reiner@ubc.ca

Received 8 March 2013 Revised 22 April 2013 Accepted 30 April 2013 Published Online First 3 June 2013

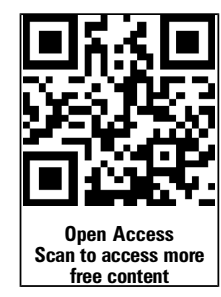

\section{SLinked}

- http://dx.doi.org/10.1136/ medethics-2013-101692

\section{CrossMark}

To cite: Fitz NS, Reiner PB. J Med Ethics 2015;41: 410-412.

\begin{abstract}
Transcranial direct current stimulation (tDCS), a simple means of brain stimulation, possesses a trifecta of appealing features: it is relatively safe, relatively inexpensive and relatively effective. It is also relatively easy to obtain a device and the do-it-yourself (DIY) community has become galvanised by reports that tDCS can be used as an all-purpose cognitive enhancer. We provide practical recommendations designed to guide balanced discourse, propagate norms of safe use and stimulate dialogue between the DIY community and regulatory authorities. We call on all stakeholdersregulators, scientists and the DIY community- to share in crafting policy proposals that ensure public safety while supporting DIY innovation.
\end{abstract}

Transcranial direct current stimulation (tDCS), a simple means of brain stimulation, has a trifecta of appealing features: it is relatively safe, relatively inexpensive and relatively effective as both treatment and as an all-purpose cognitive enhancer. ${ }^{1}$ The technique is simple yet elegant. A device sends a small current $(\sim 2 \mathrm{~mA})$ to a set of saline soaked pads that sit on the outside of one's head, and this current modulates the membrane polarity of neurons and axons within a penumbra of underlying neural tissue. The modest size of the current seems to have little effect on excitable membranes that are quiescent. However, if there is ongoing electrical activity, the change in membrane potential wrought by tDCS can facilitate either excitation or inhibition in a use-dependent manner.

\section{ETHICS OF DIY TDCS}

The range of indications for which tDCS has been explored is substantial. In the clinical realm, investigators are evaluating its use as a treatment for stroke, pain and depression, ${ }^{2}$ but the real excitement is about its use as a tool to modify the brains of healthy humans. It seems that many normal functions-working memory, numerical competence, risk-taking behaviour and more-can be either enhanced or enfeebled by tDCS. ${ }^{3}{ }^{4}$ Much as functional MRI has fuelled a revolution in measuring brain activity, tDCS seems poised to radically change our ability to manipulate brain activity in living humans. Neither technique has the resolution that the synaptically oriented neurocognoscenti might wish for, but what they lack in specificity they make up for in versatility. Together, these are the Swiss Army knives of human neuroscience.

Whereas functional MRI is expensive, even commercial tDCS devices are economical. Indeed, one virtue of the technique is that it may enable small medicine initiatives, allowing clinicians to offer inexpensive treatments to patients in both developed and developing parts of the world. The same qualities that constitute the egalitarian promise of tDCS—efficacy and access-simultaneously give rise to its peril. The modest cost of purchasing or building one's own personal tDCS device has fuelled much interest within the DIY community. ${ }^{5}$ Barely a week goes by without a new online posting either offering to sell users inexpensive tDCS devices or providing instructions for building one themselves; essentially, one needs only a $9 \mathrm{~V}$ battery, about $\$ 50$ worth of easy-to-source electronic parts and basic instructions. The challenge for the field is to develop policy that thoughtfully deals with the issues stemming from people using tDCS devices at home. ${ }^{6}$ We advocate managed technological optimism ${ }^{7}-\mathrm{a}$ perspective that acknowledges the potential for substantial benefit from the technology coupled with active oversight. We offer recommendations for scientists, journalists, commercial entities, policymakers and DIY users.

\section{BALANCE ENTHUSIASM WITH RESTRAINT}

Given the excitement that tDCS had engendered, it is unsurprising that articles in the scientific literature and the popular press enthuse about its prospects. ${ }^{8}$ Too often, these same authors give only passing reference to the concerns that might arise with misuse. Among the worries that are particularly relevant for the DIY community are:

- configuration of the device is flexible;

- reversing polarity can impair function;

- stimulation can interact with extant treatment;

- effects may be long lasting.

\section{Configuration of the device is flexible}

The placement of electrodes is crucial to obtaining reliable effects. ${ }^{9}$ An obvious problem is that of left-handed people whose brains may be organised differently from right-handed people. It is also possible that subtle differences in the neuroanatomy of individuals may alter the effects of the device.

\section{Reversing polarity can impair function}

Reversing the polarity of the electrodes may be ineffective in producing enhancement and may also result in impairment. ${ }^{10} 11$

\section{Stimulation can interact with extant treatment}

The pharmacological status of the brain can have a meaningful effect on the outcome of tDCS, ${ }^{12}{ }^{13}$ and the variety of psychoactive agents that home users may employ is legion. 


\section{Effects may be long lasting}

While tDCS has been lauded for inducing only transient changes in the brain, studies have reported effects lasting for months. ${ }^{10}$ The concern is that users may cause longlasting effects in their underlying neurobiology, including unintended and undesirable effects, which may be difficult to reverse.

We call on scientists and journalists who extol the promise of this new technology to balance their enthusiasm with more than a cursory discussion of the potential perils of tDCS. We think it prudent for those communicating the science to reflect upon the impact of value-laden words that they employ. A key example is the regular description of tDCS as non-invasive. Although the electrodes do not penetrate the brain, the electrical current must do so, as otherwise it would have no effect on neural function. Thus, tDCS is minimally invasive in some meaningful sense. Yet the technically correct descriptor 'non-invasive' carries substantial rhetorical power with regard to safety, an issue that is particularly relevant when considering DIY users. We recommend that those writing about tDCS recognise that their readership reaches beyond scientists and that their choice of words may have unexpected consequences.

\section{DEVELOP ROBUST SAFETY STANDARDS}

Although tDCS appears to be safe, the absence of obvious side effects is not evidence that the technique is unequivocally benign. We draw particular attention to the observation that if tDCS can modify intended neural functions, it may also modify unintended functions. ${ }^{14}$ In principle, tDCS may produce occult effects unseen in overt changes in cognitive function, yet may be of significance. An example of this phenomenon can be seen in studies in which tDCS stimulation of the posterior parietal cortex enhanced numerical competence, ${ }^{10}$ but it was only when automaticity was measured after such stimulation that a deficit was noted. ${ }^{14}$ Thus, the deficit, by definition, was an occult effect until specifically examined. Most worrisome, since it is well established that short-term changes in brain plasticity can morph into long-term changes, there is no fundamental reason why tDCS will not result in longlasting changes in the brain. The possibility of untoward sequelae of unwise use of tDCS - as might occur in DIY users-makes this of more than academic concern. We call on medical practitioners to put a premium on carefully designed long-term studies

\section{ENGAGE AND REGULATE}

In the USA and the European Union, devices marketed for tDCS are not covered by the existing regulatory framework. For example, recent Food and Drug Administration guidance states that, 'there is no regulation for therapeutic tDCS', ${ }^{15}$ and recent EU legislation, while less explicit about tDCS, similarly provides no regulation of tDCS devices. ${ }^{16}$ Although tDCS may come under regulatory purview in the future, tDCS devices are already being sold to the public in the USA, ${ }^{17}$ and appear poised to be sold in the EU. ${ }^{18}$ Given that the myriad applications of tDCS are fairly new, the absence of regulation is understandable. Now that tDCS devices and kits are being sold to the public, regulation is needed.

Crafting regulatory policy for DIY tDCS is challenging. First, the utility of tDCS is not strictly defined. Depending upon the specific spatial and electrical parameters employed, different cognitive functions may be modified, granting the user considerable control over critical details. Enacting regulation to cover unforeseen eventualities may be impractical. Second, the primary objective of home users is cognitive enhancement, and the regulatory authorities are not well equipped to grapple with the enhancement debate. This challenge may be tempered in the future by integrating ethical analysis into regulatory deliberations. Finally, regulating DIY tDCS is not a zero-sum game. Levying onerous requirements on DIY users may drive the work further underground to the benefit of none, while ignoring home experimentation shirks governmental responsibility to properly educate and respond to its citizens.

A responsible path forward is suggested by the approach taken to DIY by synthetic biologists (DIY BIO). In this instance, the recommendations of the National Science Advisory Board for Biosecurity spurned traditional regulatory practice in favour of open communication and education. The government opted to 'promote positive motives for participation in amateur biology and stigmatise negative ones,' in order to develop a culture of responsibility by DIY BIO practitioners. ${ }^{19}$ They then went on to create public events and conferences that prioritised direct participation in biosafety education. This strategy does not abnegate responsibility but rather offers an opportunity to gain insight into the motives of the community, allowing both groups to be better able to respond to unexpected situations.

Of course, the risk of success by DIY BIO enthusiasts is low: the Presidential Commission for the Study of Bioethical Issues concluded that technical and financial challenges are too high to develop a new organism. ${ }^{20}$ For DIY tDCS, the technical and financial challenges are modest and the likelihood of buying or building a functional device is high. Critics worry that unchecked home experimentation all but guarantees disaster. Yet classic regulatory oversight requires careful consideration of thorny issues, which are unlikely to be quickly settled. In such an interregnum, experts should have discussions with DIY practitioners in an effort to develop an ethos of responsible use. We call on all stakeholders-regulators, scientists and the DIY community itself to bring forth proposals that protect the community at large while simultaneously fostering the intellectual freedom and innovation that the DIY world champions so heartily.

Contributors NSF and PBR are both guarantors of the article confirming that the authors fulfil the criteria for authorship: they both substantially contributed to conception and design, analysis and interpretation, draft and critical revision and final approval.

Funding The authors are supported by a grant to PBR from the Canadian Institutes for Health Research and have appointments at the National Core for Neuroethics at the University of British Columbia.

\section{Competing interests None.}

Provenance and peer review Not commissioned; externally peer reviewed.

Open Access This is an Open Access article distributed in accordance with the Creative Commons Attribution Non Commercial (CC BY-NC 3.0) license, which permits others to distribute, remix, adapt, build upon this work non-commercially, and license their derivative works on different terms, provided the original work is properly cited and the use is non-commercial. See: http://creativecommons.org/ licenses/by-nc/3.0/

\section{REFERENCES}

1 Nitsche MA, Paulus W. Transcranial direct current stimulation-update 2011. Restor Neurol Neurosci 2011;29:463-92.

2 Rothwell JC. Clinical applications of noninvasive electrical stimulation: problems and potential. Clin EEG Neurosci 2012;43:209-14.

3 Cohen Kadosh R, Levy N, O'Shea J, et al. The neuroethics of non-invasive brain stimulation. Curr Biol 2012;22:108-11.

4 Hamilton R, Messing S, Chatterjee A. Rethinking the thinking cap: ethics of neural enhancement using noninvasive brain stimulation. Neurology 2011;76:187-93.

5 http://www.diytdcs.com

6 Fitz NS, Reiner PB. The perils of DIY cognitive enhancement: taking transcranial direct current stimulation seriously. The Stimulated Brain (in press: Oxford, 2013). 
7 Sarewitz D, Karas TH. Policy implications of technologies for cognitive enhancement. 2007, Sandia Report, SAND 2006-7909.

8 Snyder AW, Ellwood S, Chi RP. Switching on creativity. Sci Am Mind 2012;23: $58-62$.

9 Utz KS, Dimova V, Oppenländer K, et al. Electrified minds: transcranial direct current stimulation (tDCS) and Galvanic Vestibular Stimulation (GVS) as methods of non-invasive brain stimulation in neuropsychology - a review of current data and future implications. Neuropsychologia 2010;48:2789-810.

10 Cohen Kadosh R, Soskic S, luculano T, et al. Modulating neuronal activity produces specific and long-lasting changes in numerical competence. Curr Biol 2010;20:2016-20.

11 Javadi $A H$, Cheng $P$, Walsh V. Short duration transcranial direct current stimulation (tDCS) modulates verbal memory. Brain Stimulation 2012;5:468-74.

12 Brunoni AR, Ferrucci R, Bortolomasi M, et al. Interactions between transcranial direct current stimulation (tDCS) and pharmacological interventions in the Major Depressive Episode: findings from a naturalistic study. Eur Psychiatry. In Press, Corrected Proof available online 23 November 2012. http://www.sciencedirect.com/ science/article/pii/S0924933812001149

13 Boggio PS, Zaghi S, Villani AB, et al. Modulation of risk-taking in marijuana users by transcranial direct current stimulation (tDCS) of the dorsolateral prefrontal cortex (DLPFC). Drug Alcohol Depend 2010;112:220-5.
14 luculano T, Cohen Kadosh R. The mental cost of cognitive enhancement. J Neurosc 2013;33:4482-6.

15 U.S. Food and Drug Administration. 'Petitions to request change in classification for cranial electrotherapy stimulators' (FDA executive summary, prepared for the February 10, 2012 meeting of the Neurologic Devices Panel, 2012. http://www.fda. gov/downloads/AdvisoryCommittees/CommitteesMeetingMaterials/MedicalDevices/ MedicalDevicesAdvisoryCommittee/NeurologicalDevicesPanel/UCM290787.pdf

16 European Commission. Proposal for a regulation of the European parliament and of the council on medical devices and amending directive 2001/83/EC, regulation (EC) No 178/2002 and Regulation (EC) No 1223/2009 (EC Publication 2012/0266), 2012. http://ec.europa.eu/health/medical-devices/files/revision_docs/proposal_2012_ 542_en.pdf

17 http://www.tdcsdevicekit.com

$18 \mathrm{http}: / /$ www.foc.us

19 National Science Advisory Board for Biosecurity. Strategies to educate amateur biologists and scientists in non-life science disciplines about dual use research in the life sciences. 2011. http://oba.od.nih.gov/biosecurity/pdf/ finalnsabbreport-amateurbiologist-nonlifescientists_june-2011.pdf

20 Presidential Commission for the Study of Bioethical Issues. New directions: the ethics of synthetic biology and emerging technologies. 2010. http://www.bioethics. gov/documents/synthetic-biology/PCSBI-Synthetic-Biology-Report-12.16.10.pdf 